\section{Commentary: Minimally invasive surgery: More than meets the eye}

\author{
Subroto Paul, MD, MPH
}

Minimally invasive surgery, starting with laparoscopy and thoracoscopy and evolving into robotics, has transformed patients' surgical experience. Large open incisions are no longer a prerequisite. With smaller incisions that do not require rib spreading in the chest, patients experience pain and consequently are more mobile and recover faster. Less invasive methods do not mean poorer-quality surgery, however. In most cases, postoperative outcomes are improved, and surgical options can be extended to more frail populations with less invasive surgery. Furthermore, oncologic efficacy appears to be unchanged when using minimally invasive methods.

As more techniques are developed and applied in minimally invasive surgery, adoption accelerates. Various procedures once deemed difficult or "impossible to do" with less-invasive surgery becomes possible. Practice makes perfect, or the "10,000-hour rule," as described by Malcolm Gladwell.

In this issue of JTCVS Techniques, Alushani and colleagues $^{2}$ provide a nice illustration of this concept with thoracoscopic resection of a duplication cyst in a 5-yearold child. Technically, this surgical scenario is challenging, given the limited workspace in a small child, as well as the extent of the cyst located in among major vasculature; however, the authors successfully resected the lesion and avoided the need for a thoracotomy. The outcome would have been successful regardless of the approach; however, considerable morbidity was avoided for the child.

\footnotetext{
From Thoracic Surgical Services, RWJBarnabas Health, West Orange, NJ.

Disclosures: The author reported no conflicts of interest.

The Journal policy requires editors and reviewers to disclose conflicts of interest and to decline handling or reviewing manuscripts for which they may have a conflict of interest. The editors and reviewers of this article have no conflicts of interest.

Received for publication Aug 20, 2020; revisions received Aug 20, 2020; accepted for publication Aug 21, 2020; available ahead of print Sept 17, 2020.

Address for reprints: Subroto Paul, MD, MPH, Thoracic Surgical Services, RWJBarnabas Health, 101 Old Short Hills Rd, Ste 302, West Orange, NJ 07052 (E-mail: Subroto.Paul@rwjbh.org).

JTCVS Techniques 2020;4:386

2666-2507

Copyright (C) 2020 The Authors. Published by Elsevier Inc. on behalf of The American Association for Thoracic Surgery. This is an open access article under the CC BY-NCND license (http://creativecommons.org/licenses/by-nc-nd/4.0/).

https://doi.org/10.1016/j.xjtc.2020.08.065
}

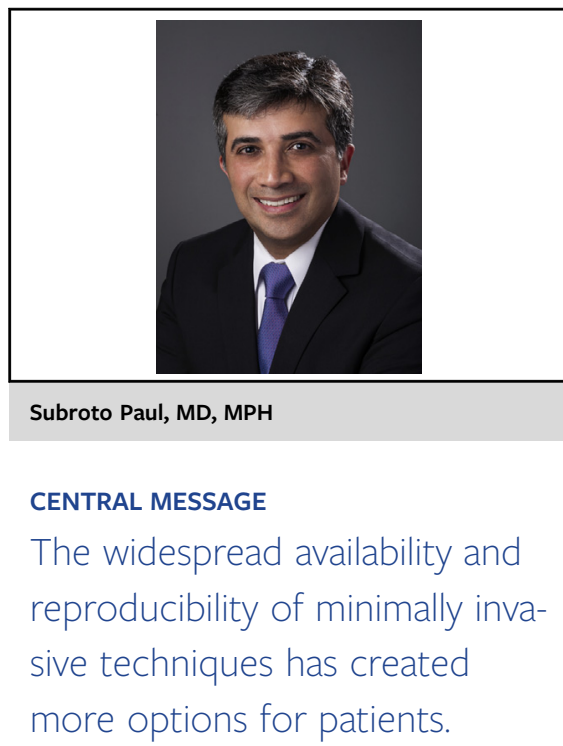

This case illustrates that as familiarity with minimally invasive techniques increases, the indications and applications for this approach increase as well. Patients are often wowed by the fact that their incisions are so small; some ask in jest how much work, if any, was done. However, the incisions of minimally invasive surgery do not do justice to the techniques developed in thoracoscopy and robotics. Much like with Transformers, the popular Japanese robotic cartoon and toy line from the 1980s, the incisions are more than meets the eye.

\section{References}

1. Gladwell M. Outliers: The Story of Success. New York: Little, Brown; 2008. 2. Alushani D, Haxhija E, Bizhga M, Saraci B, Khen-Dunlop N. Thoracoscopic resection of esophageal duplication causing tracheobronchomalacia in a 5-year-old patient. J Thorac Cardiovasc Surg Tech. 2020;4:382-5. 